\title{
Applying near Infrared Spectroscopy and iPLS to Quantitative Analysis of PHB, Poly-P, and GLY in Denitrifying Phosphorus Removal
}

\author{
Hua Zhang ${ }^{1,2}$, Changcheng Li', Jian Huang1*, Xianhuai Huang', \\ Wenchao Zhang ${ }^{1}$, Xiong Zhang ${ }^{1}$, Zhaoliang Wu ${ }^{1}$, Xiaokun Yu ${ }^{1}$ \\ ${ }^{1}$ Key Laboratory of Anhui Province of Water Pollution Control and Wastewater Reuse, School of Environment \\ and Energy Engineering, Anhui Jianzhu University, Hefei, China \\ ${ }^{2}$ Civil Engineering, National University of Ireland, Galway, Ireland
}

Received: 18 September 2017

Accepted: 3 October 2017

\begin{abstract}
Near infrared spectroscopy and interval partial least-squares (iPLS) were applied to rapid quantitative analysis of thepoly- $\beta$-hydroxybutyrate (PHB), polyphosphate (Poly-P), and glycogen (Gly) during denitrifying phosphorus removal. Wavelet denoising was used to pretreat the raw near infrared spectroscopy, and the quantitative analysis models (iPLS models) of PHB, Poly-P, and GLY were established with interval partial least-squares (iPLS). The iPLS was used to select the optimal spectral interval for modeling. The total phosphorus decreased from $7.9 \mathrm{mg} / \mathrm{L}$ to $0.67 \mathrm{ma} / \mathrm{L}$ during denitrifying phosphorus removal. The region from 4,320 to $4,640 \mathrm{~cm}^{-1}$ was selected to establish the iPLS model of intracellular PHB. The region from 4,000 to $4,320 \mathrm{~cm}^{-1}$ was selected to establish the iPLS model of intracellular Poly-P. Finally, the region from 5,103 to 5,379 $\mathrm{cm}^{-1}$ was chosen to establish the iPLS model of intracellular GLY. Statistical tests of these iPLS models of PHB, Poly-P, and GLY show that the correlation coefficients $\left(r_{c}\right)$ between the correction values and the chemical values are $0.9637,0.9582$, and 0.9437 , with the root mean square error of cross validation (RMSECV) being $0.0069,0.0039$, and 0.0025 . Test results of iPLS models show that the correlation coefficients $\left(r_{p}\right)$ between the prediction value (by iPLS model) and the chemical value were $0.9430,0.9389$, and 0.9133 , with the root mean square error of prediction (RMSEP) being $0.0523,0.0040$, and 0.0058 . These research results show that the proposed models may provide a rapid and effective quantitatively analysis of intracellular PHB, Poly-P, and GLY, and that the effect of the denitrifying phosphorus removal process can be quickly judged from the cell metabolism perspective.
\end{abstract}

Keywords: near infrared spectroscopy, iPLS, denitrifying phosphorus removal, PHB, Poly-P, GLY

*e-mail: huangjianpaper@163.com 


\section{Introduction}

Phosphorus is the main factor causing water eutrophication [1], and denitrifying phosphorus removal is a sustainable biological nitrogen and phosphorus removal process [2-3]. The metabolism of microorganisms plays an important role in denitrifying phosphorus removal [4]. Under anaerobic conditions, denitrifying phosphorus removal bacteria absorb volatile fatty acids and synthesize intracellular poly- $\beta$-hydroxybutyrate (PHB) using the energy of the degradation of intracellular polyphosphate (Poly-P) and glycogen (GLY), and then release $\mathrm{PO}_{4}^{3-}$ into the outside [5-7]. However, under anoxic conditions, denitrifying phosphorus removal bacteria decompose stored PHB as an energy source to excessively absorb $\mathrm{PO}_{4}^{3-}$ and transform it to Poly-P, replenishing GLY and cell-growth [8-11]. Therefore, the metabolism of PHB, Poly-P, and Gly are considered to determine the efficiency of denitrifying phosphorus removal [12]. So the rapid measurements of the content of intracellular PHB, Poly-P, and GLY are important for operating or regulating the denitrifying phosphorus removal process. The traditional methods to analyze intracellular PHB, Poly-P, and GLY are complicated, costing much time and resources, and often causing secondary pollution [13]. Therefore, it is of much significance to develop a rapid and pollutionfree method to analyze the content of intracellular PHB, Poly-P, and GLY.

Near infrared spectroscopy is a fast and green analytical technique. With the characteristics of simple operation, low cost, rapid analysis, less consumption of chemicals, and simultaneous measurements of multiple components [14-19], it has drawn much attention in recent years and has been widely used in food, medicine, the environment, etc. [20-28]. However, there is little research on its application for measuring intracellular PHB, Poly-P, and GLY in the denitrifying phosphorus removal process. It is often inevitable that near infrared spectra will be affected by the uneven particles distribution of samples and background noise of near infrared spectroscopy instruments. Therefore, raw near infrared spectra data should be preprocessed to eliminate such interference [29]. Wavelet denoising is an effective preprocessing method that can effectively eliminate scattering and noise [30-31]. Interval partial least squares (iPLS) is a new chemometric method developed on the basis of PLS. Compared with PLS, iPLS has better performance in quantitative analysis [32]. With the iPLS method, the full-spectra are divided into several regions and then the optimal intervals are selected to establish the quantitative analysis model (iPLS model) [33-34]. The near infrared spectroscopy combined with iPLS algorithm has achieved good results in rapid quantitative analysis of polyphenols in green tea and inorganic nitrogen in water and in the rapid diagnosis of some diseases [19].

However, as to near infrared spectroscopy combined with iPLS algorithm, there is little study on the analysis of intracellular PHB, Poly-P, and GLY in the denitrifying phosphorus removal process. Therefore, in this study wavelet denoising was used to preprocess raw near infrared spectra of samples in the denitrifying phosphorus removal process. After pretreatment, iPLS was used to select the optimum spectral interval and establish quantitative analysis models of intracellular PHB, Poly-P, and GLY. It is hoped that this study may provide a rapid and non-polluting method for the analysis of intracellular PHB, Poly-P, and GLY in the denitrifying phosphorus removal process.

\section{Material and Methods}

\section{Experimental Equipment and Water Quality}

A sequencing batch reactor was used in this experiment (Fig. 1). Denitrifying phosphorus removal was achieved by alternate anaerobic and anoxiccondition. The volume of the reactor was $15 \mathrm{~L}$. The reaction temperature was maintained as room temperature. The operational cycle was $360 \mathrm{~min}$. The influent time was $30 \mathrm{~min}$, anaerobic stage was $105 \mathrm{~min}$, anoxic stage was $150 \mathrm{~min}$, precipitation time was $25 \mathrm{~min}$, drainage was $5 \mathrm{~min}$, and stabilization time was $45 \mathrm{~min}$. The raw water quality in this experiment was as follows: $180 \mathrm{mg} / \mathrm{L}$ for COD, $7.5 \mathrm{mg} / \mathrm{L}$ for TP, $32 \mathrm{mg} / \mathrm{L}$ for $\mathrm{NH}_{4}^{+}-\mathrm{N}$, and 7.5 for $\mathrm{pH}$.

\section{Sample Collection and Analysis Method}

When the denitrifying phosphorus removal process was in stable operation, sludge samples were collected every $15 \mathrm{~min}$, and 20 samples were collected in a cycle. Finally, 140 samples were collected in 7 cycles. The 100 samples were used to establish iPLS models, and the remaining 40 samples were used to test iPLS models. All the samples were centrifuged for $5 \mathrm{~min}$, and then the sludge samples were dried for $20 \mathrm{~h}$. Every sample was divided into two sub-samples. One was measured with chemical method to get the chemical value of intracellular PHB, Poly-P, and GLY; the other was measured with near infrared spectrometer to collect spectral data. The iPLS method was employed to establish the iPLS models. Gas chromatography was used for measuring PHB. Molybdenum antimony spectrophotometric method was used for measuring Poly-P. The anthrone method was used for measuring GLY. Near infrared spectrometer was used for measuring spectral data.

\section{Establishing and Evaluating the iPLS Model}

The establishment of iPLS models includes the following steps. First, raw near infrared spectra were pretreated with wavelet denoising. Second, the full spectrum was divided into several intervals. Then independent PLS regression analysis was conducted in each subinterval, and the interval with the minimum RMSECV was the optimal modeling interval. After that, the iPLS model established in the optimal interval was 


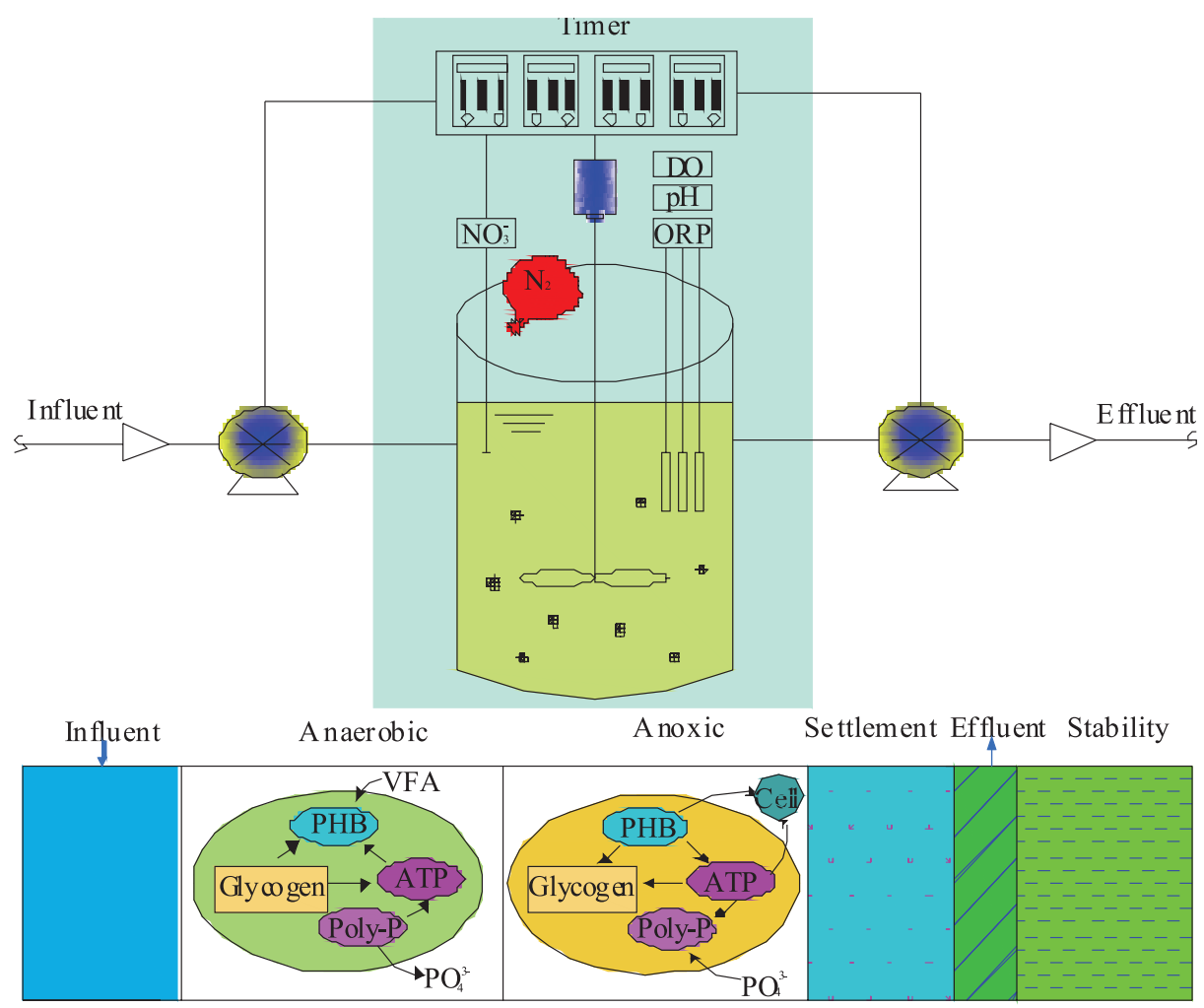

Fig. 1. Process of denitrification phosphorus removal.

the optimal model, and the accuracy of the iPLS model was evaluated with the root mean square error of cross validation (RMSECV) and the correlation coefficient $\left(r_{c}\right)$. Finally, the established models were tested, and the performance of the models was evaluated with the root mean square error of prediction (RMSEP) and the correlation coefficient $\left(r_{p}\right)$. These evaluation parameters are calculated with the following formula [35-36]:

$$
\begin{gathered}
\text { RMSECV }=\sqrt{\frac{\sum_{i=1}^{\mathrm{m}}\left(x_{i}-x_{i}^{\prime}\right)^{2}}{m-1}} \\
r_{c}=\sqrt{1-\frac{\sum_{\mathrm{i}=1}^{\mathrm{m}}\left(x_{i}-x_{i}^{\prime}\right)^{2}}{\sum_{\mathrm{i}=1}^{\mathrm{m}}\left(x_{i}-\bar{x}\right)^{2}}} \\
\operatorname{RMSEP}=\sqrt{\frac{\sum_{\mathrm{i}=1}^{\mathrm{n}}\left(y_{i}-y_{i}^{\prime}\right)^{2}}{n-1}} \\
\boldsymbol{r}_{p}=\sqrt{1-\frac{\sum_{\mathrm{i}=1}^{\mathrm{n}}\left(y_{i}-y_{\mathrm{i}}^{\prime}\right)^{2}}{\sum_{\mathrm{i}=1}^{\mathrm{n}}\left(y_{i}-\bar{y}\right)^{2}}}
\end{gathered}
$$

...where $m$ and $n$ are the numbers of the modeling sample and test sample, $x_{i}$ and $y_{i}$ are the chemical values of the modeling sample and the test sample, $x_{i}^{\prime}$ is corrected value by iPLS model, $y_{i}^{\prime}$ is predicted value by iPLS model, and $\bar{x}$ and $\bar{y}$ are the average of chemical values of the modeling sample and the test sample.

\section{Results and Discussion}

Change of Intracellular Substances of Denitrifying Phosphorus Removal Process

Fig. 2 shows the changes of intracellular substances during the denitrifying phosphorus removal process. As we can see in Fig. 2, intracellular Poly-P and GLY were decomposed to produce energy to synthesize PHB in the anaerobic stage. Therefore, the content of Poly-P

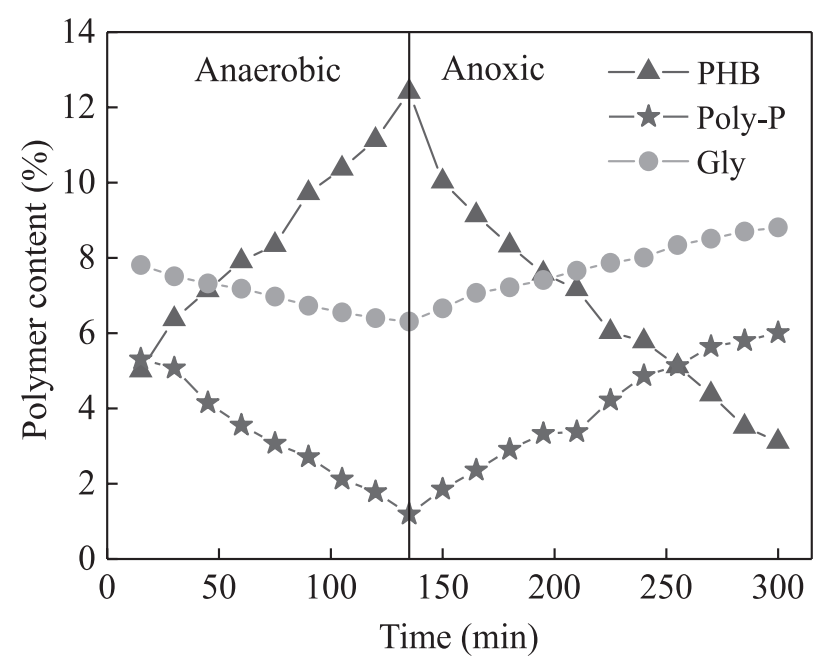

Fig. 2. Content of intracellular PHB, Poly-P, and GLY in anaerobic and anoxic phases during denitrification phosphorus removal. 


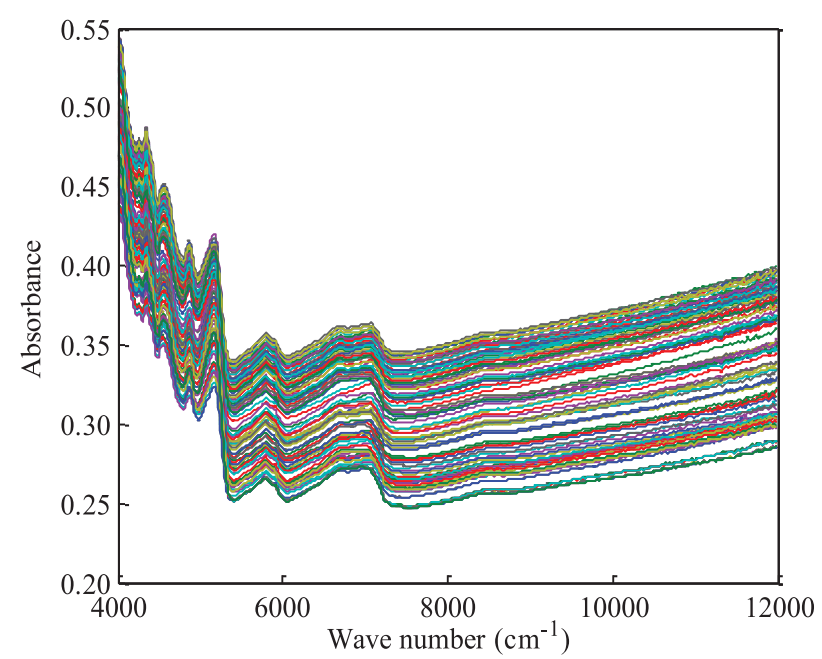

Fig. 3. Raw near infrared spectra by near infrared spectrometer.

decreased from $5.31 \%$ to $1.19 \%$, and the content of GLY decreased from $7.81 \%$ to $6.31 \%$. However, stored PHB is decomposed during tne anoxic stage, producing energy to absorb phosphate from sewage and to synthesize Poly-P and GLY. The content of PHB decreased from 12.41\% to $3.11 \%$, the content of Poly-P increased from $1.19 \%$ to $6.01 \%$, and the content of GLY increased from $6.31 \%$ to $8.81 \%$. These data show that the denitrifying phosphorus removal process has been stable.

\section{Pretreatment of Raw Near Infrared Spectra}

The raw near infrared spectra of the samples are shown in Fig. 3. The $\mathrm{X}$-axis is the wave number, which ranges from 4,000 to $12,000 \mathrm{~cm}^{-1}$, and the Y-axis is the absorbance of near infrared spectra. Fig. 3 shows that there are similar shape and change in the raw near infrared spectra of all the samples. However, the raw near infrared spectra are also affected by the uneven distribution of particles and instrument noise. Therefore, there are scattering and noise signals in raw near infrared

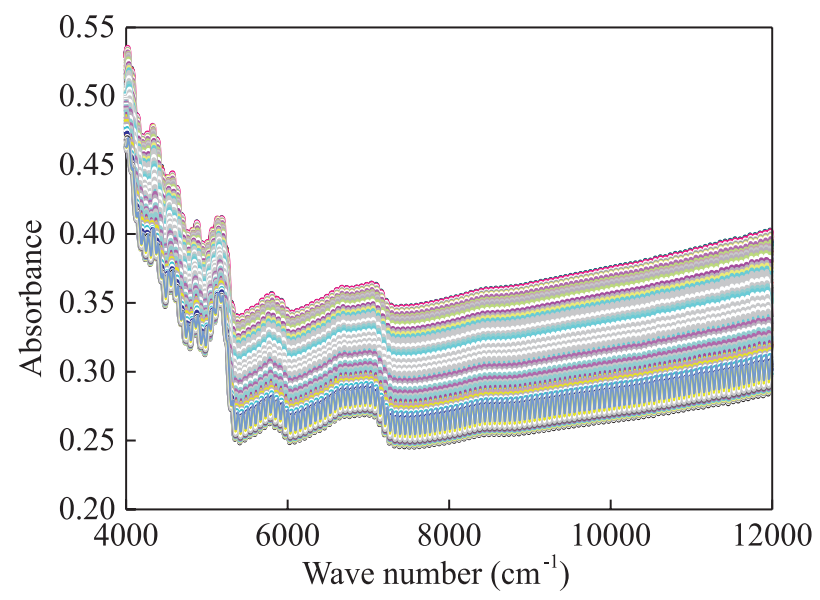

Fig. 4. Pretreated spectra of sludge samples; wavelet denoising was used to pretreat the spectra.

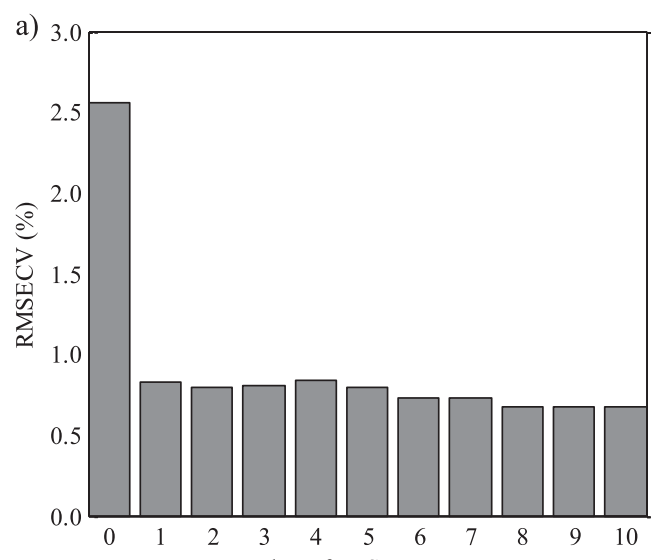

b)

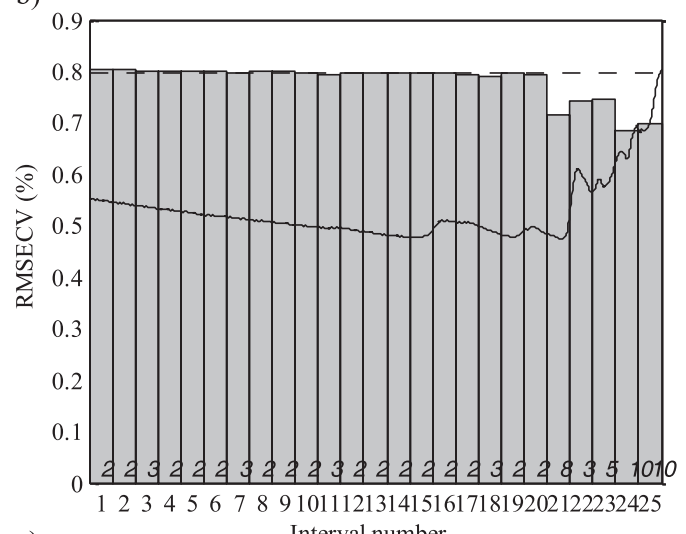

c)

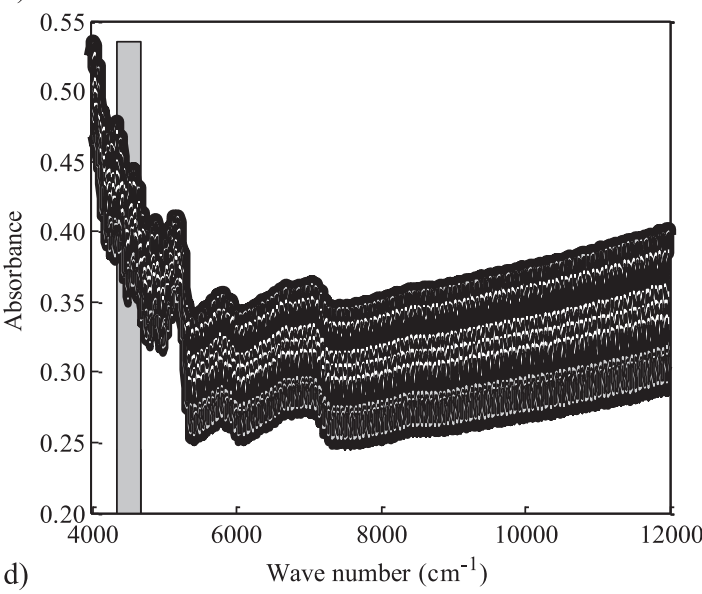

d)

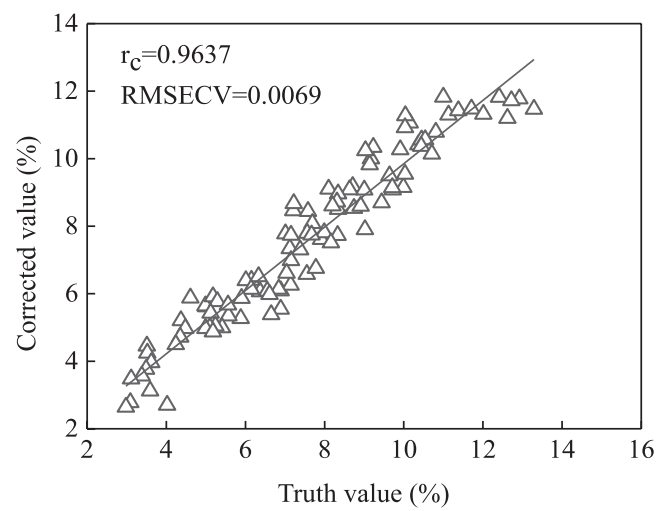

Fig. 5. Establishing the iPLS model of PHB: a) change of RMSECV in full spectrum, b) change of RMSECV in each interval, c)s elected wave number, and d) iPLS model of Poly-P; linear correlation between the corrected value and the truth value of PHB. 
Table 1. Selected wave band, optimal internal, principle component number, and evaluation parameters of PHB, Poly-P, and GLY.

\begin{tabular}{|c|c|c|c|c|c|c|c|}
\hline $\begin{array}{c}\text { Intracellular } \\
\text { polymer }\end{array}$ & $\begin{array}{c}\text { Selected wave band } \\
\left(\mathrm{cm}^{-1}\right)\end{array}$ & Optimal internal & $\begin{array}{c}\text { Principle component } \\
\text { number }\end{array}$ & $r_{\mathrm{c}}$ & RMSECV & $r_{\mathrm{p}}$ & RMSEP \\
\hline PHB & $4320-4640$ & 24 & 10 & 0.9637 & 0.0069 & 0.9430 & 0.0523 \\
\hline Poly-P & $4000-4320$ & 25 & 2 & 0.9582 & 0.0039 & 0.9389 & 0.0040 \\
\hline GLY & $5103-5379$ & 25 & 9 & 0.9437 & 0.0025 & 0.9133 & 0.0058 \\
\hline
\end{tabular}

spectra, especially in the wave number of 4,000 to $5,000 \mathrm{~cm}^{-1}$, where a large number of burr peaks appear. These interferences will affect the true characteristic signal of the substances. So effective pretreatment is necessary to obtain desired spectral information and improve the accuracy of the quantitative analysis model. Fig. 4 shows near infrared spectra pretreated with wavelet denoising. After pretreatment, the interferences in the raw near infrared spectra were effectively reduced, and the near infrared spectra are smoother.

\section{Establishing the iPLS Model}

After pretreatment by wavelet denoising, the near infrared spectra $\left(4,000-12,000 \mathrm{~cm}^{-1}, 1,037\right.$ spectral data) were divided into several intervals by iPLS. Then the interval with the minimum RMSECVV was selected as the optimal interval, and the iPLS model in the optimal interval was the best model.

\section{Establishing the iPLS Model of Intracellular PHB}

Establishing the iPLS model of intracellular PHB is shown in Figs 5(a-d) and Table 1. In the full-spectrum, the RMSECV changed with the principal component number (Fig. 5a), and the minimum RMSECV is $0.69 \%$ when the principal component number is 10 . Then the full spectrum is divided into 25 intervals. For each internal, the optimal principal component number and the corresponding RMSECV are shown in Fig. 5b). The italic number in the bar column of each interval represents the optimum principal component number of the interval, and the height of each column presents the RMSECV of the corresponding interval. In addition, the dotted line represents the minimum RMSECV in full spectrum. As shown in Figs 5(b-c), the RMSECV of the $24^{\text {th }}$ interval $\left(4,320-4,640 \mathrm{~cm}^{-1}\right)$ is the minimum compared with fullspectrum, with RMSECV being $0.69 \%$. Therefore, the $24^{\text {th }}$ interval is the optimal interval for modeling, which has the characteristics of higher information content. In this interval, the iPLS model of intracellular PHB was considered the best model (Fig. 5d). In Fig. 5d), the $X$ axis is the chemical value of intracellular PHB, and the $\mathrm{Y}$ axis is the corrected value of the iPLS model. The $r_{c}$, between the chemical value and the correction value, is 0.9637 , and the corresponding RMSECV is 0.0069 . The result shows that the iPLS model of intracellular PHB has a good correction effect.

\section{Establishing the iPLS Model of Intracellular Poly-P}

Figs 6(a-d) show the establishment of an iPLS model of intracellular Poly-P, and Fig. 6a) shows the RMSECV changes with the number of principal components in the full-spectrum. In the full-spectrum, the minimum RMSECV is $0.39 \%$, with the principal component number being 2. Fig. 6b) showed the optimal principal component number and the RMSECVs of 25 intervals. As can be seen from Figs 6(b-c), the RMSECV is the minimum in the 25th interval $\left(4,000-4,320 \mathrm{~cm}^{-1}\right)$, with the RMSECV being 0.0039 . Therefore, the 25 th interval is considered the optimal interval, and the iPLS model in this interval was considered a good model for intracellular Poly-P (Fig. 6 d). In Fig. 6d), the $X$ axis and $Y$ axis respectively represent the chemical value and the corrected value. Between the chemical value and the correction value, $r_{c}$ is 0.9582 and the corresponding RMSECV is 0.0039 . The result shows that the iPLS model of intracellular Poly-P has a satisfying effect of correction.

\section{Establishing the iPLS Model of Intracellular GLY}

The establishment of the iPLS model of intracellular GLY are presented in Figs 7(a-d) and Table 1. Fig. 7a) shows how RMSECV changes with different numbers of principal components. The RMSECV is the minimum $(0.25 \%)$ when the principal component number is 9 . The full spectrum is divided into 29 subintervals (Fig. 7b). As can be seen from Figs 7(b-c), the RMSECV of the $25^{\text {th }}$ interval $\left(5,103-5,379 \mathrm{~cm}^{-1}\right)$ is the minimum $0.25 \%$. Therefore, the $25^{\text {th }}$ interval is the optimal interval. The established model is shown in Fig. 7d. The $r_{c}$ between the chemical value and the correction value is 0.9437 , with the RMSECV being 0.0025 . These results indicate that the iPLS model of intracellular GLY has a perfect correction effect.

\section{Tests of iPLS Models of Intracellular PHB, Poly-P, and GLY}

The established iPLS models of intracellular PHB, Poly-P, and GLY were tested on the basis of the data of the 40 samples that were not used in modeling. The test results are shown in Fig. 8, where the $\mathrm{X}$ axis is the chemical value and the $\mathrm{Y}$ axis is the prediction value by iPLS models. The test results of iPLS model of PHB 

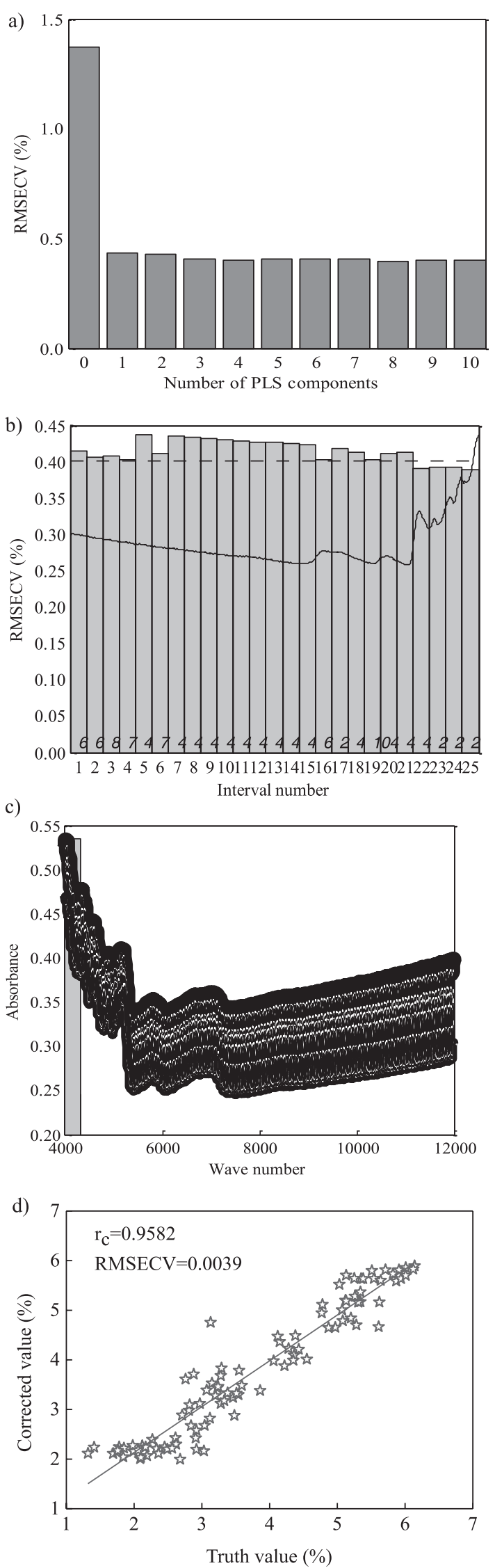

Fig. 6. Establishing the iPLS model of Poly-P: a) change of RMSECV in full spectrum, b) change of RMSECV in each interval, c) selected wave number, and d) iPLS model of Poly-P; a linear correlation between the corrected value and the truth value of Poly-P.
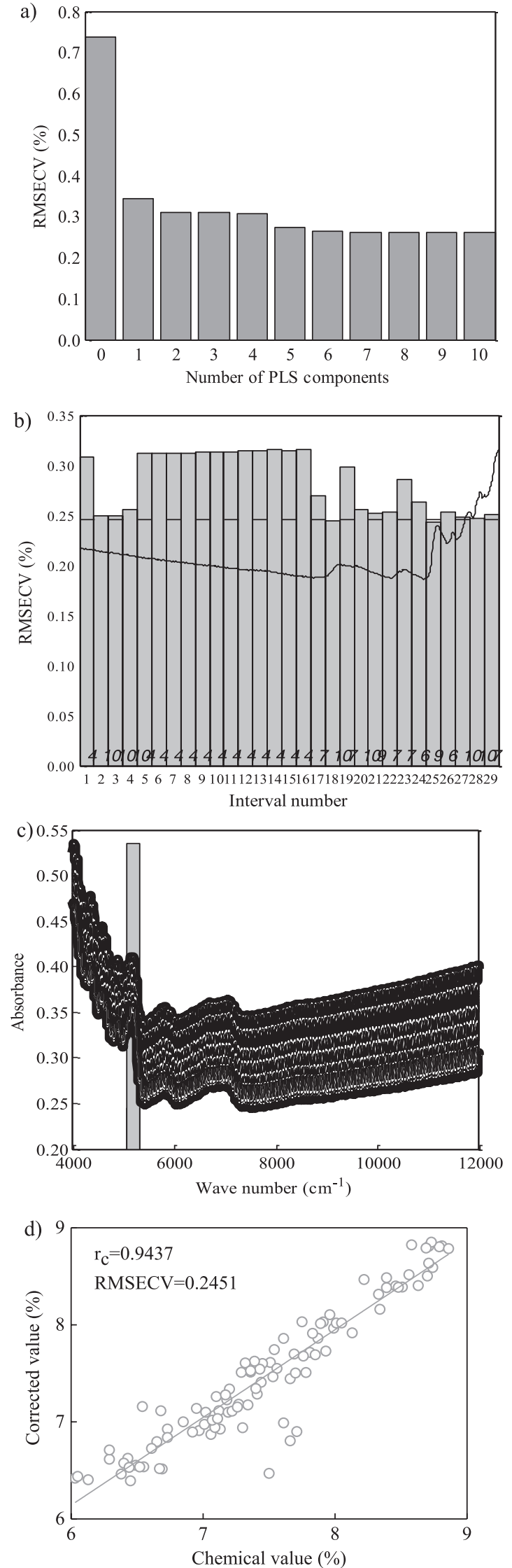

Fig. 7. Establishing the iPLS model of GLY: a) change of RMSECV in full spectrum, b) change of RMSECV in each interval, c) selected wave numberb, and d) iPLS model of GLY; a linear correlation between the corrected value and the truth value of GLY. 
shows that, between the prediction value and the chemical value, $r_{p}$ is 0.9430 , and the root mean square error of prediction (RMSEP) is 0.0052 . The test result of the iPLS model of Poly-P shows that, between the prediction value and the chemical value, the $r_{p}$ is 0.9389 and the root mean square error of prediction is 0.0040 . The test results of iPLS model of GLY show that between the prediction
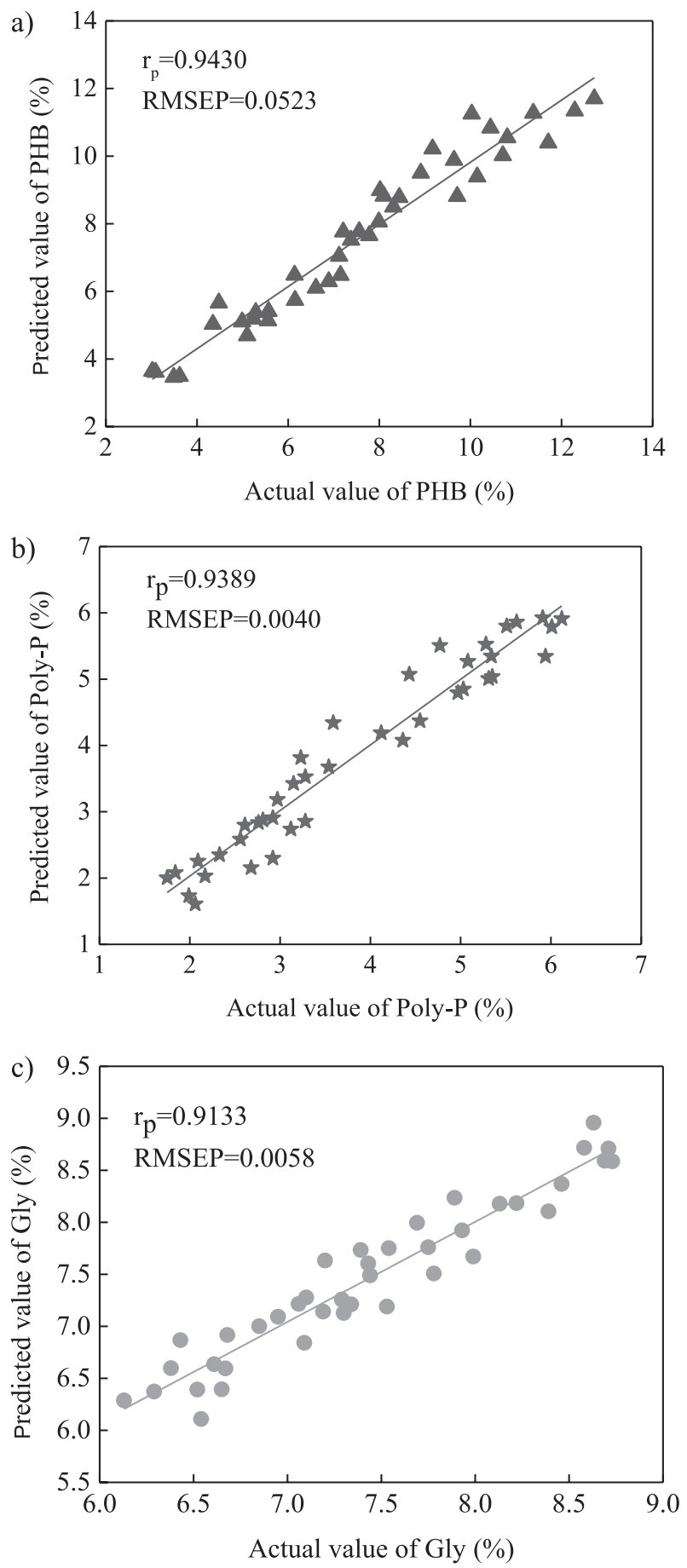

Fig. 8. Test of iPLS models: a) a linear correlation between the predicted value and the chemical value of PHB, b) a linear correlation between the predicted value and the chemical value of Poly-P, c) a linear correlation between the predicted value and the chemical value of GLY. value and the chemical value, the $r_{p}$ is 0.9133 and the root mean square error of prediction (RMSEP) is 0.0058 . These results show that the iPLS models are capable of satisfactorily and promptly predicting the content of intracellular PHB, Poly-P, and GLY.

\section{Conclusions}

A fast and effective method for proving quantitative analysis for intracellular PHB, Poly-P, and GLY was developed based on near infrared spectroscopy. The noise of raw near infrared spectra may be reduced by wavelet denoising, and the effective spectral information was extracted. The established quantitative analysis models that make use of the iPLS algorithm are powerful analytical tools for intracellular PHB, Poly-P, and GLY. The feasibility of the iPLS models based on near-infrared spectroscopy was evaluated by root mean square error of cross validation and correlation coefficient. In addition, the performance of iPLS models was validated by test samples, thereby demonstrating their capability as simple, fast analytical tools for intracellular PHB, Poly-P, and GLY. These results demonstrated that the iPLS models of intracellular PHB, Poly-P, and GLY are rapid and reliable for detecting and quantifying the content of intracellular PHB, Poly-P, and GLY in denitrification phosphorus removal. In the future, the influence of different pretreatment methods or different modeling methods on the rapid analysis of intracellular substances should be researched further.

\section{Acknowledgements}

This research was supported by Anhui Province Natural Science Foundation (1808085MB34), the Research Projects of Visiting Scholars for Excellent Young and Backbone Talents both at Home and Abroad for Colleges of Anhui Province (gxfx2017054), Key Projects to Support the Talent for Colleges of Anhui Province (gxyqZD2017059), and the Major Science and Technology Program for Water Pollution Control and Treatment of China (2014ZX07405-003-03).

\section{References}

1. DODDS W.K., SMITH V.H. Nitrogen, phosphorus, and eutrophication in streams. Inland Waters, 6 (2), 155, 2016.

2. ZHANG H., TIAN J.Y., HUANG J., HUANG X.H., QUAN G.J., YAN S., LIU P.R. Rapid and pollutionfree characterization of intracellular polyphosphate and orthophosphate using mid-infrared spectroscopy combined with chemometrics in the denitrifying phosphorus removal process. RSC Advances, 6 (111), 110356, 2016.

3. LV X.M., SHAO M.F., LI C.L., LI J., GAO X.L., SUN F.Y. A comparative study of the bacterial community in denitrifying and traditional enhanced biological phosphorus removal processes. Microbes and environments, 29 (3), 261, 2014. 
4. ZHANG H.L., FANG W., WANG Y.P., SHENG G.P., ZENG R.J., LI W.W., YU H.Q. Phosphorus Removal in an Enhanced Biological Phosphorus Removal Process: Roles of Extracellular Polymeric Substances.Environmental Science \& Technology. 47 (20),11482, 2013.

5. ZHANG H., ZHU J., SONG J., HUANG J., ZHANG Y., WANG K., HUANG S.Infrared spectrum analysis of PHB and the correlation between PHB reduction and orthophosphate removal rate during denitrifying phosphorus removal.Research of Environmental Sciences. 28, 1274, 2015.

6. AN H.X, MO C.R., LI X.M., SUN W.B., CUI W., LIU K. Thestudy on denitrificayion and denitrifying phosphorus removal process by the intracellular polymers. Technology of Water Treatment. 39 (9), 116, 2013.

7. LV D.M., PENGY. Z., ZHAO W.H., WANG S.Y., ZENG W. Factors influencing the denitrifying phosphorus removal efficiency of A2O-BAF process. China Environmental Science. 35 (11), 3266,2015.

8. ZENG W., ZHANG J., WANG A., PENG Y. Denitrifying phosphorus removal from municipal wastewater and dynamics of "Candidatus Accumulibacter" and denitrifying bacteria based on genes of ppk1, narG, nirS and nirK. Bioresource Technology. 207, 322, 2016.

9. WANG Y., ZHOU S., WANG H., YE L., QIN J., LIN X.M. Comparison of endogenous metabolism during long-term anaerobic starvation of nitrite/nitrate cultivated denitrifying phosphorus removal sludges. Water Research. 68, 374, 2015.

10. WANG Y., GUO G., WANG H., STEPHENSON T., GUO J., YE L. Long-term impact of anaerobic reaction time on the performance and granular characteristics of granular denitrifying biological phosphorus removal systems. Water Research. 47 (14), 5326, 2013.

11. WONG P.Y., CHENG K.Y., KAKSONEN A.H., SUTTON D.C., GINIGE M.P. A novel post denitrification configuration for phosphorus recovery using polyphosphate accumulating organisms.Water Research. 47 (17), 6488, 2013.

12. WENTZEL M.C., LOTTER L.H., LOEWENTHAL R.E., GVR M. Metabolic behavior of Acinetobacter spp. in enhanced biological phosphorus removal - A biochemical model. Water SA. 12 (4), 209,1986.

13. MUHR A., RECHBERGER E.M., SALERNO A., REITERER A., MALLI K., STROMEIER K., SCHOBER S., MITTELBACH M., KOLLER M. Novel description of mcl-PHA biosynthesis by Pseudomonas chlororaphis from animal-derived waste.Journal of Biotechnology. 165 (1), 45, 2013.

14. WANG Y., ZHOU S., YE L., WANG H., STEPHENSON T., JIANG X. Nitrite survival and nitrous oxide production of denitrifying phosphorus removal sludges in longterm nitrite/nitrate-fed sequencing batch reactors. Water Research. 67, 33, 2014.

15. LI C., WANGT T., ZHENG N., ZHANG J., NGO H.H., GUO W., LIANG S. Influence of organic shock loads on the production of $\mathrm{N}_{2} \mathrm{O}$ in denitrifying phosphorus removal process.Bioresource Technology. 141 (4), 160, 2013.

16. WANG R.C., SI S.P., YANG D.H., LI J.Q., ZHAO J.F. Effects of temperature on denitrifying phosphorus removal in enhanced biological phosphorus removal (EBPR) process. Acta Scientiae Circumstantiae. 33 (6), 1535, 2013.

17. PAN T., HAN Y., CHEN J., YAO L., XIE J. Optimal partner wavelength combination method with application to nearinfrared spectroscopic analysis.Chemometrics \& Intelligent Laboratory Systems. 156, 217,2016.
18. LIANG C., YUAN H.F., ZHAO Z., SONG C.F., WANG J.J. A new multivariate calibration model transfer method of near-infrared spectral analysis. Chemometrics \& Intelligent Laboratory Systems. 153, 51, 2016.

19. HUANG J., HUANG S., ZHANG H., HUANG X.H., ZHANG Y., WANG M., ZHU J., WANG K. Near infrared spectroscopy analysis of inorganic nitrogen in shortcut nitrification-denitrification based on interval partial least square. China Environmental Science. 35 (7), 2014, 2015.

20. CHIESA L., PANSERI S., BONACCI S., PROCOPIO A., ZECCONI A., ARIOLI F., CUEVAS F.J., MORENOROJAS J.M. Authentication of Italian PDO lard using NIR spectroscopy, volatile profile and fatty acid composition combined with chemometrics. Food Chemistry. 212, 296, 2016.

21. PASCOA-RNMJ., LOPO M., SANTOS-CATD., GRACA A.R., LOPES J.A. Exploratory study on vineyards soil mapping by visible/near-infrared spectroscopy of grapevine leaves. Computers \& Electronics in Agriculture. 127, 15, 2016.

22. LI H., YAO Q., FAN J., DU J., WANG J., PENG X. An NIR fluorescent probe of uric HSA for renal diseases warning. Dyes \& Pigments. 133, 79, 2016.

23. WANG C., ZHAO N., FANG L., ZHANG T., FENG Y. Void fraction measurement using NIR technology for horizontal wet-gas annular flow.Experimental Thermal \& Fluid Science. 76, 98,2016.

24. ZHAO M., DOWNEY G., O'DONNELL C.P. Exploration of microwave dielectric and near infrared spectroscopy with multivariate data analysis for fat content determination in ground beef. Food Control. 68, 260, 2016.

25. ZHU F.L., HE Y., SHAO Y.N. Application of near-infrared hyperspectral imaging to predicting water content in salmon flesh. Spectroscopy \& Spectral Analysis. 35 (1), $113,2015$.

26. ZANGERLE A., HISSLER C., MCKEY D., LAVELLE P. Using near infrared spectroscopy (NIRS) to identify the contribution of earthworms to soil macroaggregation in field conditions.Applied Soil Ecology. 104, 138, 2016.

27. PAN T., LI M., CHEN J. Selection method of quasicontinuous wavelength combination with applications to the near-infrared spectroscopic analysis of soil organic matter.Applied Spectroscopy. 68 (3), 263, 2014.

28. NAN Q.U., ZHU M.C., DOU S. Application of Near-and Mid-infrared Diffuse Reflectance Spectroscopic Techniques in Soil Analysis. Journal of Instrumental Analysis. 34, 120,2015.

29. ZHANG H., QUAN G.J., HUANG J., HUANG X.H., Y AN S., LIU P.R., LIU H., TIAN J.Y. Study on intracellular polymers using near infrared spectroscopy and extreme learning machine in denitrifying phosphorus removal process.China Environmental Science. 37 (5), 1823, 2017.

30. ALSBERG B. K., WOODWARD A.M., WINSON M.K., ROWLAND J., KELL D.B. Wavelet denoising of infrared spectra. Analyst, 122 (7), 645, 1997.

31. LIAO Y., FAN Y., CHENG F. On-line prediction of pH values in fresh pork using visible/near-infrared spectroscopy with wavelet de-noising and variable selection methods. Journal of food engineering, 109 (4), 668, 2012.

32. ZHOU X.H., ZHANG M., XIANG B.R. Determination of acid value of peanut oil by near-infrared spectrometry Combined with interval partial least squares. Science and Technology of Cereals,Oils and Foods. 25 (2), 62, 2017. 
33. RAHMAN A., KONDO N., OGAWA Y., SUZUKI T., KANAMORI K. Determination of $\mathrm{K}$ value for fish flesh with ultraviolet-visible spectroscopy and interval partial least squares (iPLS) regression method. Biosystems Engineering.141,12, 2016.

34. BERGHOLT M.S., HASSING S. Quantification of C-Reactive protein in human blood plasma using near-infrared Raman spectroscopy.Analyst. 134 (10), 2123, 2009.
35. JOVIC O. Durbin-Watson partial least-squares regression applied to MIR data on adulteration with edible oils of different origins. Food Chemistry. 213, 791, 2016.

36. DING X., HAN S., YANG H.H., XU J., YANG G. A Study of Recognition Algorithms of Large-Scale Image Based on the Fusion of SIFT Features and BP Neutral Network. Advanced Materials Research. 1049-1050, 1558, 2014. 
